\title{
Demonstration of substances capable of contracting smooth muscle in the haematoma fluid from certain cases of ruptured cerebral aneurysm
}

\author{
MONAMY BUCKELL \\ From the Neurosurgical Research Laboratories, Atkinson Morley's Hospital (Branch of St. Georges Hospita䲩, \\ Wimbledon, London
}

In a proportion of patients suffering rupture of an intracranial aneurysm, the angiogram demonstrates marked narrowing of the vessels in the proximity of the lesion. These appearances are considered by many neurosurgeons and neuroradiologists to be due to active constriction of the affected vessels.

Others, however, deny the very existence of this phenomenon as far as cerebral vessels are concerned and explain the appearances on the grounds of atherosclerosis, stretching of the vessels by local haematoma or brain swelling, or to inadequate filling with contrast material. To the surgeon who has experience of direct surgical approaches to intracranial aneurysms, the development of marked vasoconstriction is an observable phenomenon: manipulation, for example, of the middle cerebral artery to dissect out an aneurysm will often result in marked shrinkage of the main vessel and its peripheral branches to half their original calibre. This is, of course, a mechanically induced constriction of the vessels.

If the phenomenon is accepted, the causation is not clear, but among the various possibilities, the most popular is that such a change could be produced or maintained by a chemical agent liberated locally in relation to the haemorrhage.

The point is one of importance as there is no doubt that patients with angiograms showing evidence of this vascular narrowing fare worse with surgical intervention when compared with those patients showing vessels of normal calibre.

To test this theory, we examined nine specimens of haematoma material taken from the immediate environment of a ruptured aneurysm. The material was collected at craniotomy undertaken for direct attack upon the aneurysm and thus the most dangerously ill patients were excluded as being unsuitable for this form of treatment (category A cases). In many other patients the quantity of haematoma fluid was too small or was evacuated by suction before a specimen could be obtained.
MATERIAL AND METHOD

The samples consisted of a mixture of old fluid blood with varying amounts of clot, cerebrospinal fluid, and flecks of necrotic brain tissue. Amounts ranging from 0.2 to $2.9 \mathrm{~g}$. were obtained from the immediate neighbourhood of the aneurysm and its parent vessel. In case 1 subdural fluge was also obtained and in case 2 there was a specimen of cerebrospinal fluid that had been taken six days prooperatively and stored frozen. The material was collected with a siliconed syringe or a scoop and transferred toia silicone-coated container. Some specimens reachedōthe laboratory within half an hour; others, taken at anophes hospital, were transported without refrigeration but minimal delay, the slowest taking three and a half hours. To avoid activation of protease-peptide systems by eo tact with glass, which was thought to have occurred some earlier cases excluded from this series, all handi iog up to the time of testing was carried out in silicone-coateg glassware.

The fluid specimens were centrifuged, or in the case of the mainly solid ones a saline extract was made, and te supernatant fluid was separated. In four cases this was tested at once on a preparation that had been set up anticipation of a specimen.The other supernatants wege frozen immediately and stored at $-15^{\circ} \mathrm{C}$. for the periods shown in the Table.

For the determination of total smooth-muscle-contra $\overrightarrow{\overrightarrow{0}}$ ing activity and of true 5-hydroxytryptamine (5-HT) co

\section{TABLE}

ACTIVITY OF HAEMATOMA FLUIDS FROM RUPTURED CEREBRAL ANEURYSMS

\begin{tabular}{|c|c|c|c|c|}
\hline \multirow[b]{2}{*}{$\begin{array}{l}\text { Case } \\
\text { No. }\end{array}$} & \multicolumn{4}{|c|}{ CEREBRAL ANEURYSMS } \\
\hline & $\begin{array}{l}\text { Arterial } \\
\text { Narrowing }\end{array}$ & $\begin{array}{l}\text { Days between } \\
\text { Most Recent } \\
\text { Haemorrhage } \\
\text { and Operation }\end{array}$ & $\begin{array}{l}\text { No. of } \\
\text { Days } \\
\text { Specimen } \\
\text { Stored }\end{array}$ & $\begin{array}{ll}\text { Total } & \text { 5-HT } \\
\text { Activity } & \text { (ng.pe } \\
\text { Expressed } & \text { of } \\
\text { as HT Units specin }\end{array}$ \\
\hline
\end{tabular}

\begin{tabular}{|c|c|c|c|c|c|}
\hline $\begin{array}{l}1 \\
2 \\
3 \\
4 \\
5 \\
6 \\
7 \\
8 \\
9\end{array}$ & $\begin{array}{l}\text { Yes } \\
\text { Yes } \\
\text { Yes } \\
\text { Yes } \\
\text { No } \\
\text { No } \\
\text { No } \\
\text { No } \\
\text { No }\end{array}$ & $\begin{array}{r}3 \\
12 \\
3 \\
3 \\
2 \\
2 \\
4 \\
2 \\
7 \\
6\end{array}$ & $\begin{array}{l}\mathbf{1} \\
1 \\
\mathbf{0} \\
\mathbf{1} \\
\mathbf{4} \\
\mathbf{0} \\
\mathbf{0} \\
\mathbf{2} \\
\mathbf{0}\end{array}$ & $\begin{array}{c}60 \\
80 \\
147 \\
20 \\
25 \\
33 \\
12 \cdot 5 \\
17 \cdot 5 \\
64\end{array}$ & 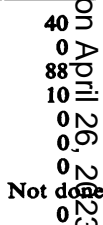 \\
\hline & & & & & $\frac{\text { 음 }}{\mathrm{C}}$ \\
\hline
\end{tabular}


tent the rat stomach strip method of Vane (1957) was used, with addition of UML-491 (Methysergide) as a blocking agent for 5-HT. Only preparations capable of detecting one nanogram (ng.) of 5-HT in the test dose were used. Where activity was too high to record, dilutions were made in physiological saline. Saline alone had no effect on the preparation but in some specimens dilutions led to an increase of total activity, suggestive of a polypeptide. The total activity of the specimen in terms of standard 5-HT and of acetylcholine was determined, UML-491 was then added to the superfusion fluid to give a concentration of $10^{-8}$. At this concentration UML-491 did not change the sensitivity of the preparation to acetylcholine while it completely inhibited 5-HT. The assay was then repeated in terms of acetylcholine and the proportion of the total activity due to 5-HT was calculated as the decrease of activity relative to acetycholine after the addition of the 5-HT inhibitor.

\section{RESULTS}

The table gives the total activity of each specimen and the actual amount of 5-HT found. The total activity is expressed as equivalents of 5-HT, though not necessarily all due to this substance, 1 'HT unit' being the amount of activity that gave rise to a contraction equivalent to that produced by 1 nanogram of 5-HT. In addition, the subdural fluid from case 1 had a total activity of 22 'HT-units' of which $4 \mathrm{ng}$. per $\mathrm{ml}$. was 5 -HT, and the cerebrospinal fluid from case 2 contained 8 units of total activity per $\mathrm{ml}$. of which $50 \%$ was 5 -HT.

The finding of 5-HT in cases 1,3 , and 4 and its absence from the four control cases gives a possible chemical explanation for the local state of the vessels. Case 2 did not come to operation until 12 days after the more recent of his two subarachnoid haemorrhages and seven days after the arteriogram. At this time spasm was presumed on clinical grounds still to be present, but the intense spasm seen at the time of arteriography could have lead to infarction. The patient died 11 days post-operatively and an extensive area of cerebral infarcation was seen at necropsy.
Though a high total activity was found no true 5-HT could be demonstrated in the operation specimen from this case. However, the cerebrospinal fluid taken on the day after the arteriogram had one of the highest total activities we have yet found in this material and contained $4 \mathrm{ng}$. 5-HT per ml.

Raynor, McMurtry, and Pool (1961) showed that topically applied 5-HT could constrict the exposed cerebral vessels of cats, though they failed to obtain a reaction to cerebrospinal fluid from three cases of subarachnoid haemorrhage. We started by examining lumbar cerebrospinal fluid but then decided that the material in contact with the vessels would be more informative and so have been concentrating on specimens removed at operation. The conclusion cannot be drawn that 5-HT is in fact responsible for the arterial narrowing in our patients as there is other material also present in excess in the affected cases; also the chemical differences might be a sequel of the vascular disturbance rather than a cause of it. This small series of results can only point the way to further investigation, but the preliminary findings are reported at this stage as we believe that this is the first demonstration of a chemical difference in the immediate surroundings of affected and unaffected vessels. As a potentially vasoconstrictor substance with known antagonists is involved, the confirmation of its presence by other workers and perhaps by other methods is of importance. Meanwhile we are extending our series of cases and also pursuing the nature of the non-HT activity.

We are grateful to the Wolfson Foundation for financial support, to Drs. J. R. Vane and J. W. Thompson, of the Department of Pharmacology, Royal College of Surgeons, for advice and help with the pharmacological technique, and to Messrs. Sandoz Products Ltd. for a gift of UML-491.

\section{REFERENCES}

Raynor, R. B., McMurtry, J. G., and Pool, J. L. (1961). Neurology (Minneap.), 11, 190.

Vane, J. R. (1957), Brit. J. Pharmacol., 12, 344 